\title{
Effects of reward distribution strategies and perseverance profiles on agent-based coalitions dynamics
}

\author{
Efeitos de estratégias de distribuição de recompensas e perfis de perseverança na \\ dinâmica de coalizões baseadas em agentes
}

\author{
Luís Gustavo Ludescher ${ }^{1 *}$, Jaime Simão Sichman ${ }^{1}$
}

\begin{abstract}
In a conventional political system, leaders decide how to distribute benefits to the population and coalitions can emerge when other individuals support the candidates. This work intends to analyze how different leader strategies and individual profiles affect the way coalitions are formed and rewards are shared. Using agent-based simulation, we simulated a model in which individuals of three different perseverance profiles (patient, intermediate and impatient) eventually decide to be part of coalitions by supporting certain leaders when aiming to maximize their own earnings. Leaders can follow one of three different strategies to share rewards: altruistic, intermediate and egoistic. The results show that egoistic leaders stimulate the competition for rewards and the formation of coalitions, causing greater inequalities, while impatient individuals also promote more instability and lead to a higher concentration of rewards.
\end{abstract}

Keywords: Agent-based simulation — Coalitions — Public welfare — Inequality

Resumo: Em um sistema político convencional, líderes decidem como distribuir benefícios à população e coalizões podem emergir quando outros indivíduos apoiam os candidatos. Este trabalho se propõe a analisar como diferentes estratégias de líderes e perfis de indivíduos afetam a maneira como coalizões são formadas e recompensas são compartilhadas. Usando simulação baseada em agentes, nós simulamos um modelo no qual indivíduos de três diferentes perfis de perseverança (paciente, intermediário e impaciente) eventualmente decidem fazer parte de coalizões apoiando certos líderes com o objetivo de maximizar seus próprios ganhos. Líderes podem seguir uma dentre três diferentes estratégias para compartilhar recompensas: altruísta, intermediária e egoísta. Os resultados mostram que líderes egoístas estimulam a competição por recompensas e a formação de coalizões, causando mais desigualdade, e indivíduos impacientes também promovem mais instabilidade e levam a uma maior concentração de recompensas.

Palavras-Chave: Simulação baseada em agentes - Coalizões - Bem-estar público — Desigualdade

${ }^{1}$ Laboratório de Técnicas Inteligentes (LTI), Escola Politécnica, Universidade de São Paulo, Brasil

*Corresponding author: Igludescher@usp.br

DOI: http://dx.doi.org/10.22456/2175-2745.98845 • Received: 25/07/2019 • Accepted: 27/09/2019

CC BY-NC-ND 4.0 - This work is licensed under a Creative Commons Attribution-NonCommercial-NoDerivatives 4.0 International License.

\section{Introduction}

In experimental economics, prosocial attitudes have been studied in the Public Goods Game [1]. In its standard version, an equal amount of coins is given to the players at the beginning of the game. Then, in each round, every player confidentially decides how many coins, if any, he wants to put in a public pot. At the end of the round, the number of coins contained in the pot is increased by a gain factor between one and the number of players, representing a cooperation bonus, and the resulting amount is equally shared among all players. Collectively, the best situation is when every player offers all his coins to the public pot, which maximizes the total amount of coins available in the system. In contrast, from an individual perspective, a single player gets the highest gain by not offering any coins to the pot. So, considering that it is not possible to make agreements nor to retaliate, since the decision of each player is confidential, the game theoretically ends without any player putting coins in the pot. However, experiments presented in [1] indicate that in real life initially there may be some level of cooperation. They show that in the first rounds some players tend to put coins in the pot, while others eventually also decide to cooperate when they notice that someone is doing so. Nevertheless, such behavior ends 
up disappearing after a certain number of rounds.

Burger and Kolstad [2] propose a scenario in which forming coalitions is allowed in the context of the Public Goods Game. In such a scenario, the players choose, in each round, to be part or not of a coalition before deciding how many coins to contribute. Each member of a coalition informs his preference about contributing or not to the public goods and all members of the coalition follow the decision of the majority. Finally, the amount collected is equally divided among all players. In this way, being part of a coalition reduces the risk of the contribution, since a member of a coalition contributes to the public goods only when the other members do the same. However, it diminishes the autonomy of a player, since his action is dependent on the majority decision. Moreover, the mentioned work includes a case in which there is a degree of uncertainty about receiving rewards. In this case, there is a previously known probability that no reward will be distributed in a round, but the expected overall return is maintained. The study experimentally evaluates the impact of coalition formation and uncertainty on contribution patterns and also relates the sizes of coalitions to the experimental settings. Their results show that: (i) contributions to the public goods are increased when forming coalitions is allowed; (ii) coalitions are larger as the potential individual reward increases; and (iii) contributions tend to decrease with increasing uncertainty.

Hamman et al. [3] also analyze scenarios in which coalitions may be formed, but in their experiments a leader of a coalition is responsible for deciding each member's contribution. In the same way as in the standard model, the amount collected is equally divided among all players. Basically, the study compares three scenarios: (i) a decentralized one, in which players voluntarily decide how much to contribute; (ii) a centralized one, in which players have to select a leader who is in charge of deciding how much each player should contribute in that round; and (iii) a flexible one, in which every player can choose to be part of a coalition, delegating his decision to a leader, or not. The study also evaluates the impact of allowing communication between players in each of the three scenarios. The results obtained in this work show that: (i) the decentralized scenario leads to low collective efficiency since contributions tend to decrease dramatically, even though performance is improved when communication is allowed; (ii) the centralized scenario is the most efficient one, since players tend to select leaders who maximize collective contributions and avoid selfish leaders; and (iii) the flexible scenario is efficient only when communication is allowed, facilitating cooperation between players, thus fostering trust and stimulating the formation of coalitions.

On the other hand, there are two main characteristics that differ the standard Public Goods Game from an ordinary political system: in reality, people usually have to pay mandatory taxes, avoiding the free-rider problem. Moreover, political representatives are in charge of administering the public goods and have to decide, at least partially, which interests, groups and regions to serve and which goods and services to offer, usually leading to an unequal distribution of benefits. Even if such real system prevents people from deciding not to offer public contributions, on the other hand certain individuals, expecting some kind of benefit in the future, can form coalitions to fund the campaign of candidates for political offices. This kind of strategy may result in uneven sharing of benefits [4], so that political representatives serve only restricted parts of the population.

Our proposal is to develop and simulate a simplified model of such an ordinary political system. The proposed model is inspired in the Public Goods Game, but also consider the main characteristics of real political systems. In our work, we consider a society composed of individuals who seek to maximize their profits, and may eventually support certain leaders by forming or joining coalitions. In each cycle of a simulation, a leader from one of the coalitions becomes the political representative of that round and has the role of distributing rewards among all the individuals. We also consider that leaders can follow different strategies to distribute rewards and individuals can have distinct perseverance profiles, which are related to their expectations about rewards.

In such a context, the purpose of this work is to analyze the effects of different combinations of leader welfare distribution strategies and individual perseverance profiles on coalition dynamics and reward sharing. In other words, we aim to answer the following question: how different leader strategies and individual perseverance profiles affect the dynamics of coalitions and the distribution of rewards? So, we expect that, on one hand, the more leaders prioritize their own coalitions, the stronger the competition for rewards, leading to the formation of large coalitions. On the other hand, the higher the expectations of individuals, the greater the tendency for concentration of rewards, increasing inequality.

Our work offers an alternative approach that can help to understand the nature of some structural shortcomings of current political systems. On one hand, the results obtained could guide the definition of new regulations to increase the efficiency of the systems. On the other hand, such results could also guide people both to choose better leaders and understand the importance of more collaborative behaviors.

In section 2, we briefly introduce agent-based coalitions. We then present our model in Section 3, followed by our experimental results in Section 4. Finally, in Section 5 we present our conclusions and further work.

\section{Agent-based Coalitions}

Agents have an incentive to form coalitions when cooperating with each other may be more advantageous than acting alone [5]. Since each member decides to remain in the coalition based on its rewards, the coalition stability depends on how the benefits are shared. Theoretically, the reward of a member should be defined based on his effective contribution to the entire coalition [6] and the optimal solution for such a problem is known as the Shapley Value. Thus, forming a coalition 
would, ideally, only make sense if the collective benefits are greater than the combined individual earnings of its members.

Nardin et al. [7] show an interesting model involving agent-based coalitions in which the agents are arranged in a grid and compete for earnings. Each agent keeps track of its neighbors' gains and try to get better rewards by joining or forming coalitions with those neighbors that get more benefits. Eventually, an agent with good performance becomes leader of a coalition, whose role is to collect the rewards of all members and redistribute them equally after charging a fee for the task.

Since it is subjective to determine the effective contribution of an agent to a coalition, as well as its perception about the fairness of its rewards, generally it is only possible to estimate the Shapley Value. Thus, if a leader is in charge of sharing rewards among coalition members, such a leader should try to do so in a way that keeps the coalition cohesive.

To the best of our knowledge, there are few works that use agent-based coalitions and simulation in the context of political organization, dynamics of parties, election of representatives, public investments or social inequality. Muis [8] simulates an agent-based model of party competition and validates the results using past data on Dutch party competition. Valkering et al. [9] propose an agent-based game for modeling cultural and behavioral change in the context of water management and they use the concept of coalition to model groups of different positions on water policies.

In [10], Schreiber simulates the dynamics of political parties using coalitions in an agent-based model. At each iteration, agents seek to form coalitions with others of similar political positions until they achieve a majority. Although the political position of a coalition represents the average positions of its members, it can be altered to attract new members, but whenever a member does not consider himself represented by his coalition anymore, he may leave it. The work shows that using such a simple set of rules is possible to have results similar to those presented in the classic models of party dynamics.

In Ludescher and Sichman [11], we have presented the preliminary results of our work. We built and simulated an agent-based model in which the individuals sought to maximize their earnings by participating or not in coalitions. Three different leader strategies were considered: altruistic leaders distributed rewards more equally, while egoistic ones offered greater rewards for their coalitions, and finally the intermediate leaders had a in-between strategy. The results showed that egoistic leaders stimulate the formation of more coalitions and cause more instability.

In the sequence, we present an enhanced formulation of this model, where we consider not only different leader strategies, but also individual perseverance profiles.

\section{Model}

Using agent-based simulation techniques [12], we built and simulated a model in which a network of agents represents a society of individuals. Initially, all agents receive an equal amount of resources, or capital, which can be used both to pay a mandatory tax and to eventually fund a leader. In every round, individuals interact with each other, leaders emerge (any individual can become a leader) and coalitions are formed. One of the coalitions is then declared the winner of the round and its leader becomes the political representative. As such, he is in charge of collecting taxes, increasing the amount collected by a gain factor and deciding how to share the final amount among the population. At the end of a round, individuals evaluate their rewards, update their trust on their leaders and decide, based on their satisfaction, whether they should remain in their current coalition or enter in a new and different one.

\subsection{Scenario}

A scale-free network [13] is used to link the individuals. In this type of network, the probability of a node to receive a new connection is proportional to the number of connections it already has, causing many nodes to have few connections while a few nodes have many (hubs). We selected this type of network to our model because it has a structure similar to real social networks. We chose a well-known method to set the network, based on the Barabási-Albert model [14], as it is one of the most widely used methods for forming such networks and is relatively simple to implement.

\subsection{Gain Factor}

Likewise the Public Goods Game [1], our model also uses a gain factor to increase the amount collected by taxes, representing the gain generated through cooperation. We also attribute different gain factors to different individuals, since we can assume that each leader has a distinct ability to administer the public goods.

\subsection{Strategies and Profiles}

In our model we defined two roles: the leader and the individual. On one hand, a leader role is related to what strategy he will follow to distribute rewards if he becomes a political representative, as explained in [11]. Such a strategy is modeled as a reward factor that determines how much of the total amount the leader is willing to offer for his own coalition members. In this model, three different leader distribution strategies are considered: (i) egoistic, who offers more benefits for his own coalition members; (ii) altruistic, who distributes the benefits more equally; and (iii) intermediate, who uses a in-between strategy.

On the other hand, an individual profile is related to how much reward an individual expects to receive and how many rounds he is willing to support a coalition while waiting for any greater rewards. In this way, we defined three different individual perseverance profiles: (i) impatient, who expects to receive greater rewards faster; (ii) patient, who can wait longer for better rewards; and (iii) intermediate, whose perseverance falls between both previous ones. 


\subsection{Simulation Cycle}

The simulation executes several rounds of a main cycle, composed by five steps, as shown in Pseudo-algorithm 1. Each of those steps is detailed in the next subsections.

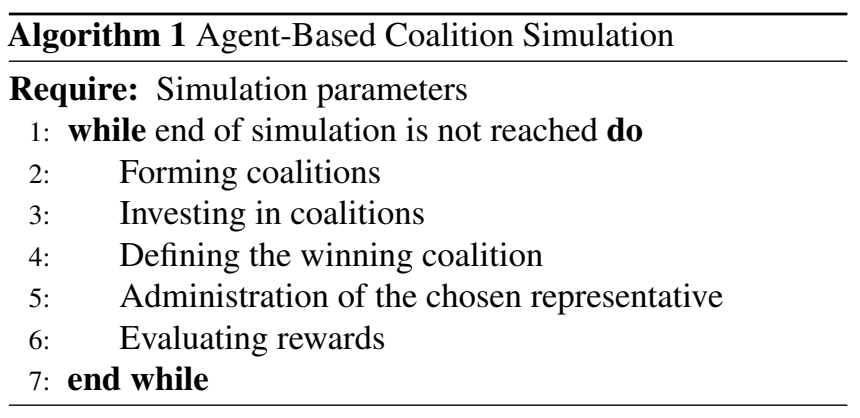

\subsubsection{Forming coalitions}

Pseudo-algorithm 2 illustrates the first step. Based on certain probability (probLeader), some individuals initially express interest in running for leaders. The chance of someone to be interested to run decreases as the number of coalitions increase, since opportunities diminish as competition increases. Based on another probability (probCoalition), each individual then decides whether to seek a coalition or not. In case the individual decides to seek, he randomly looks for a neighbor who belongs to a coalition or who wants to be a leader; otherwise, he remains independent in that round. Once in a coalition, the individual's trust in his new leader is initialized to a default value. Additionally, trust values on previous leaders of previous rounds are not reset, which means that an individual does not accept having a leader in whom he does not trust anymore.

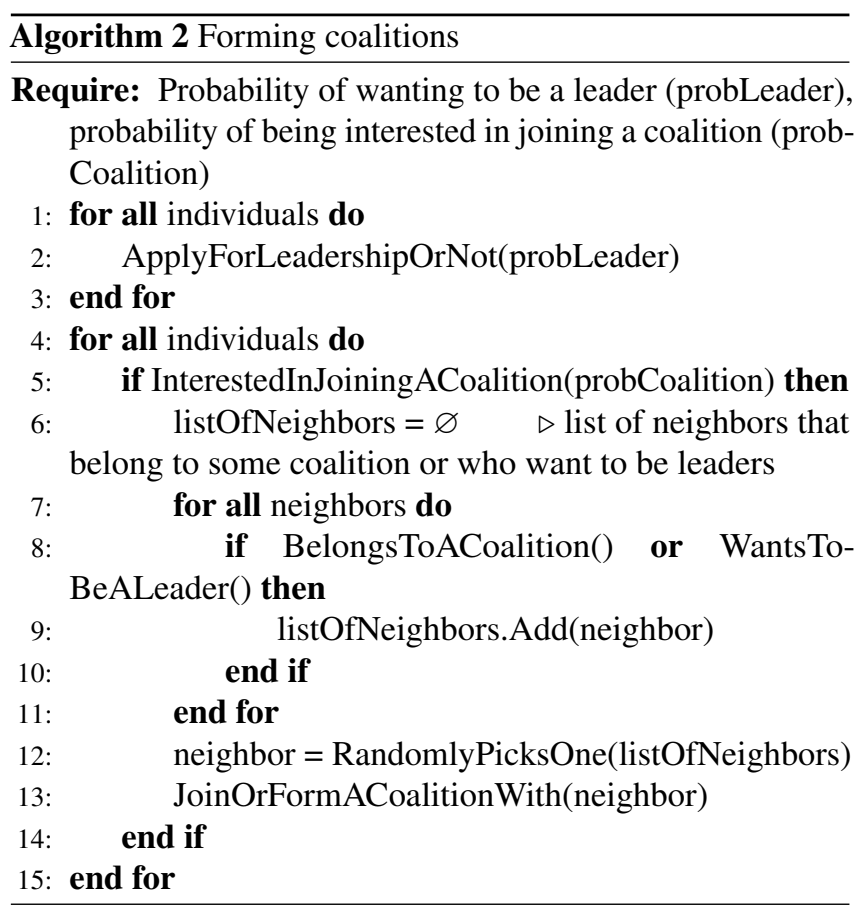

\subsubsection{Investing in coalitions}

In the following step, every coalition member invests a certain percentage of his available capital in his coalition, as illustrated in Pseudo-algorithm 3. Depending on whether the individual gets satisfied or not with the rewards received, he can, respectively, increase or decrease the value of the investment, as detailed in subsection 3.4.5.

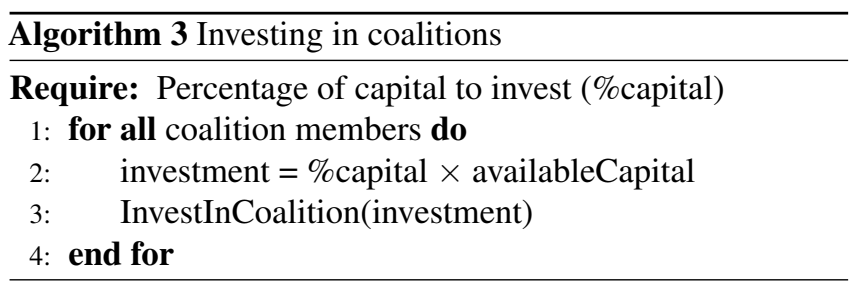

\subsubsection{Defining the winning coalition}

The likelihood for a coalition to win a round is given by the amount of received investment divided by the total investment in all coalitions, as shown in Pseudo-algorithm 4. This is analogous to a simplified scenario where the chance of a political campaign to succeed is to some extent proportional to how much investment it has received. So, the leader of the winning coalition becomes the political representative of that round.

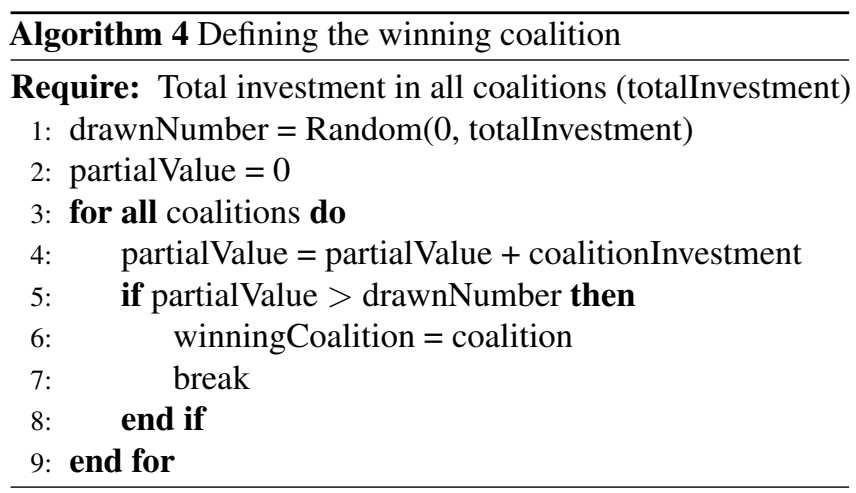

\subsubsection{Administration of the chosen representative}

In this step, the leader initially collects a parameterized tax (taxCollected), which is set up before the simulation starts (see subsection 4.1). The leader then multiplies the amount obtained by his own gain factor, resulting in the final value of the rewards to be shared. Depending on his strategy, he then defines how much of the total amount will be awarded to his own coalition and distributes it proportionally to the investment of each member. Finally, the remaining amount is distributed equally to the rest of the population, which includes members of other coalitions and independent individuals. This procedure is detailed in Pseudo-algorithm 5.

\subsubsection{Evaluating rewards}

The rewards are evaluated by each individual, as presented in Pseudo-algorithm 6. 


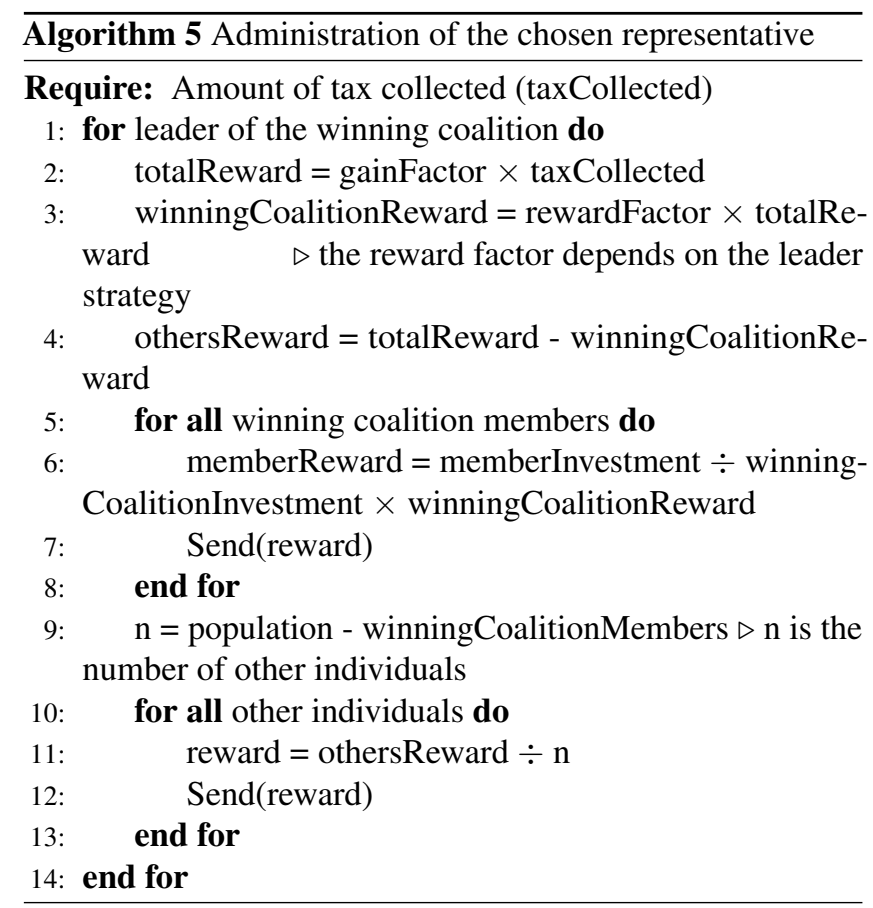

This evaluation takes into account both its relation to the winning coalition and its perseverance profile, which defines a satisfaction threshold. Patient individuals accept lower returns than impatient ones, and impatient individuals decrease their trust in the leaders faster than patient ones. This procedure occurs as follows:

- Members of the winning coalition compare the reward received with their accumulated investment in the coalition. If a member gets satisfied, his trust in the leader increases, otherwise, it drastically decreases. If the trust falls below his profile threshold, the individual leaves the coalition;

- Members of other coalitions decrease the trust in their respective leaders. Again, if the trust falls below his profile threshold, the individual leaves the coalition;

- Independent individuals evaluate their rewards. The degree of satisfaction of an independent individual depends on its individual profile. If he gets satisfied, the probability of the individual wanting to form or join a coalition in the next round decreases, otherwise, it increases.

\section{Experiments}

We used the Repast ${ }^{1}$ agent-based simulation tool [15] and the ReLogo programming language [16] to implement the model.

\subsection{Description}

The experiments were conducted with the objective of analyzing the impact of different leader and individual profiles

\footnotetext{
${ }^{1}$ https://repast.github.io/
}

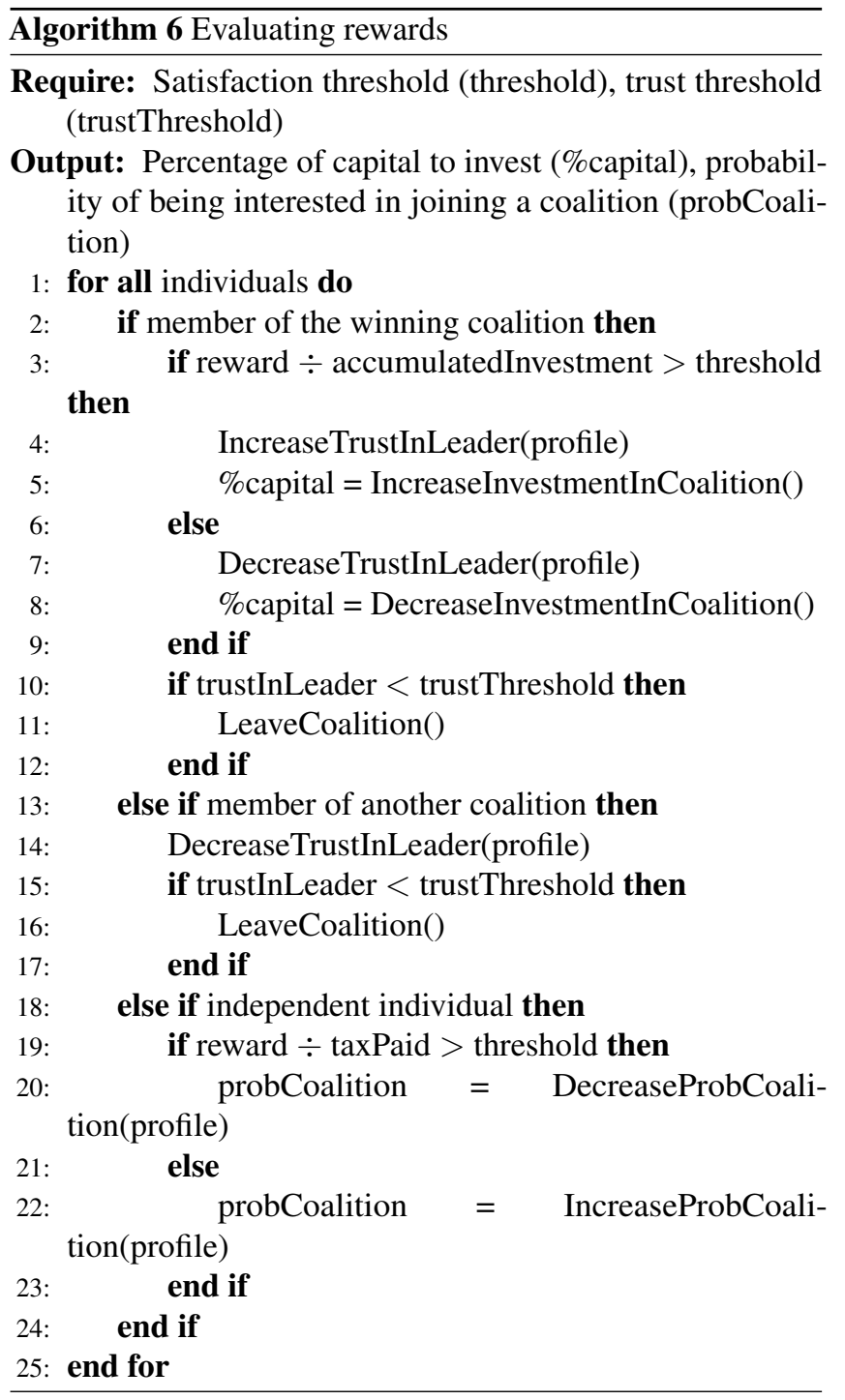

on system's dynamics. For this, as shown in Table 1, we defined 16 experiment settings by combining 4 different leader strategy configurations with 4 different individual profile configurations. In both cases, the 4 configurations included each of the three profiles separately and a fourth one that mixed the three profiles in equal proportion. Moreover, as indicated in Table 2, every experiment was run for 1000 rounds and included 1000 individuals, each of whom received an initial capital of 1000 at the beginning and had to pay 1 of tax every round. Each experiment setting was repeated 30 times, totaling 480 experiments. We present in the sequence the average and the standard deviation of the obtained results for each setting.

\subsection{Analysis of Results}

We analyzed the results in two different dimensions. First, we made a temporal analysis based on data collected during each simulation setting. This analysis helped to verify the evolution of some global variables, like the number of coalitions and 
Table 1. Experiment Settings

\begin{tabular}{|c|c|c|}
\hline Setting & Leader Strategy & Individual Profile \\
\hline$\# 1$ & Altruistic & Patient \\
\hline$\# 2$ & Altruistic & Intermediate \\
\hline$\# \mathbf{3}$ & Altruistic & Impatient \\
\hline$\# 4$ & Altruistic & Mixed \\
\hline$\# 5$ & Intermediate & Patient \\
\hline$\# 6$ & Intermediate & Intermediate \\
\hline$\# 7$ & Intermediate & Impatient \\
\hline$\# 8$ & Intermediate & Mixed \\
\hline$\# 9$ & Egoistic & Patient \\
\hline$\# 10$ & Egoistic & Intermediate \\
\hline$\# 11$ & Egoistic & Impatient \\
\hline$\# 12$ & Egoistic & Mixed \\
\hline$\# 13$ & Mixed & Patient \\
\hline$\# 14$ & Mixed & Intermediate \\
\hline$\# 15$ & Mixed & Impatient \\
\hline \#16 & Mixed & Mixed \\
\hline
\end{tabular}

Table 2. Simulation Parameters

\begin{tabular}{|l|c|}
\hline Number of rounds per experiment & 1000 \\
\hline Number of individuals per experiment & 1000 \\
\hline Initial capital per individual & 1000 \\
\hline Individual tax per round & 1 \\
\hline Number of experiments for each setting & 30 \\
\hline
\end{tabular}

coalition members, the amount of investments in coalitions and the average capital available. We then performed a distribution analysis of both capital among the population and members among the coalitions based on data collected at the end of each simulation setting. Such analyses are described in the following subsections. The tables presented show the means and standard deviations for each experiment setting. The graphics, in turn, show the evolution of the variables either for each leader strategy or for each perseverance profile, while fixing the other profile type to a certain value. In most graphics, the line corresponding to mixed strategies/profiles has been suppressed for ease of viewing, highlighting the differences between the three strategies/profiles separately.

\subsection{Temporal Analysis}

Table 3 presents the average number of coalitions for each experiment setting. It shows a clear pattern in which more coalitions are formed in the presence of altruistic leaders and patient individuals, as it can also be seen in Figures 1 and 2 . However, Table 4 shows that the total number of coalition members is much higher in scenarios with egoistic and also intermediate leaders, as illustrated in Figure 3, decreasing in the presence of impatient individuals, as shown in Figure 4. This occurs because, on one hand, altruistic leaders do not offer enough incentive to retain the members of their coalitions, leading individuals to move from one coalition to another. This results in a higher number of coalitions, but also in a lower number of individuals interested in joining coalitions.
On the other hand, coalitions led by egoistic leaders tend to be much larger, because they offer greater benefits to their members. Furthermore, impatient individuals are more difficult to satisfy, which explains why both the number of coalitions and the number of coalition members are lower in scenarios with them. We can also observe that in cases with mixed profiles, the results are relatively close to those obtained in scenarios with intermediate profiles. More specifically, in the case of mixed leader strategies, the egoistic strategy seems to exert a little more influence on the results, probably because individuals tend to prefer egoistic leaders if they are available.

Table 3. Number of Coalitions

\begin{tabular}{|c|c|c|c|c|}
\hline Individual & \multicolumn{4}{|c|}{ Leader Strategy } \\
\cline { 2 - 5 } Profile & Altruist & Intermed. & Egoist & Mixed \\
\hline Patient & $27 \pm 7$ & $15 \pm 5$ & $12 \pm 3$ & $13 \pm 4$ \\
\hline Intermed. & $22 \pm 7$ & $13 \pm 3$ & $11 \pm 3$ & $12 \pm 3$ \\
\hline Impatient & $16 \pm 7$ & $10 \pm 2$ & $9 \pm 2$ & $10 \pm 2$ \\
\hline Mixed & $24 \pm 8$ & $14 \pm 3$ & $13 \pm 3$ & $13 \pm 3$ \\
\hline
\end{tabular}

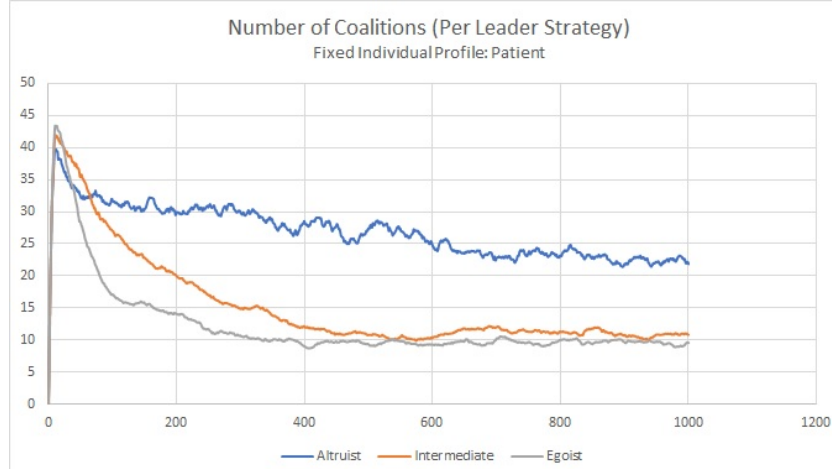

Figure 1. Number of Coalitions Per Leader Strategy (settings \#1, \#5 and \#9)

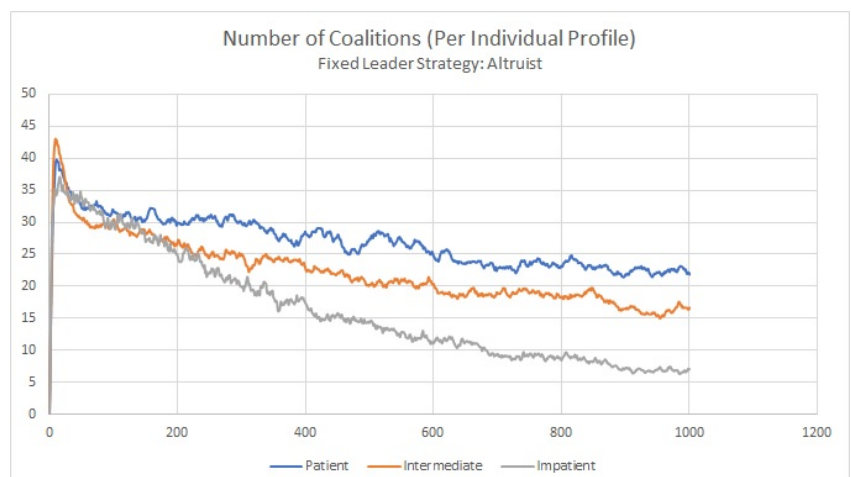

Figure 2. Number of Coalitions Per Individual Profile (settings \#1, \#2 and \#3)

In addition, we can then observe the average number of members per coalition presented in Table 5, which can be obtained by dividing the values of Table 4 by those of Table 3 . Figures 5 and 6 also show the number of members per coalition, respectively for each leader strategy and for each 
Effects of reward distribution strategies and perseverance profiles on agent-based coalitions dynamics

Table 4. Number of Coalition Members

\begin{tabular}{|c|c|c|c|c|}
\hline Individual & \multicolumn{4}{|c|}{ Leader Strategy } \\
\cline { 2 - 5 } Profile & Altruist & Intermed. & Egoist & Mixed \\
\hline Patient & 200 & 447 & 474 & 463 \\
& \pm 87 & \pm 72 & \pm 58 & \pm 65 \\
\hline Intermed. & 239 & 376 & 396 & 383 \\
& \pm 82 & \pm 46 & \pm 45 & \pm 46 \\
\hline Impatient & 153 & 189 & 189 & 185 \\
& \pm 43 & \pm 25 & \pm 29 & \pm 27 \\
\hline Mixed & 195 & 345 & 356 & 349 \\
& \pm 73 & \pm 35 & \pm 31 & \pm 34 \\
\hline
\end{tabular}

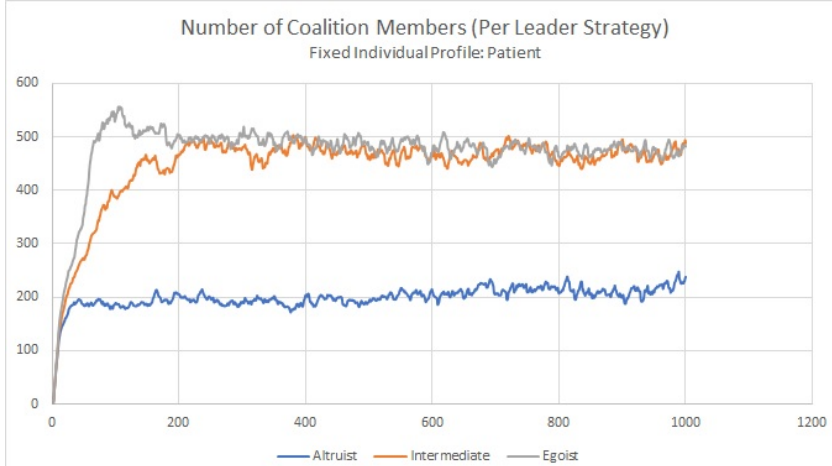

Figure 3. Number of Coalition Members Per Leader Strategy (settings \#1, \#5 and \#9)

perseverance profile. We can notice that with altruistic leaders, although many coalitions are formed, they remain very small, indicating a possible volatility. But in scenarios with egoistic leaders, in which there are fewer coalitions, they concentrate more members and are possibly more stable. Moreover, with impatient individuals not only are there few coalitions but they are also small, because if a coalition has many impatient members it will no longer be satisfactory to those members, who expect very large rewards.

Table 5. Number of Members Per Coalition

\begin{tabular}{|c|c|c|c|c|}
\hline Individual & \multicolumn{4}{|c|}{ Leader Strategy } \\
\cline { 2 - 5 } Profile & Altruist & Intermed. & Egoist & Mixed \\
\hline Patient & 7.4 & 29 & 38.4 & 34.4 \\
\hline Intermed. & 10.7 & 28.8 & 34.7 & 32.7 \\
\hline Impatient & 9.3 & 19.4 & 20 & 19.1 \\
\hline Mixed & 8 & 25.1 & 28.3 & 27.1 \\
\hline
\end{tabular}

Table 6 presents results consistent with the previous analysis. In scenarios with altruistic leaders, the investments in coalitions tend to be lower, but higher with egoistic leaders, since the latter give more benefits to their coalitions, as shown in Figure 7. We can also observe from Table 6 that the standard deviations are especially high with altruistic leaders. Since they offer to their coalitions a smaller part of the total reward, such coalitions have more room to receive increasing investments. Even if they are not very attractive, a few members who remain satisfied continue to increase their investments

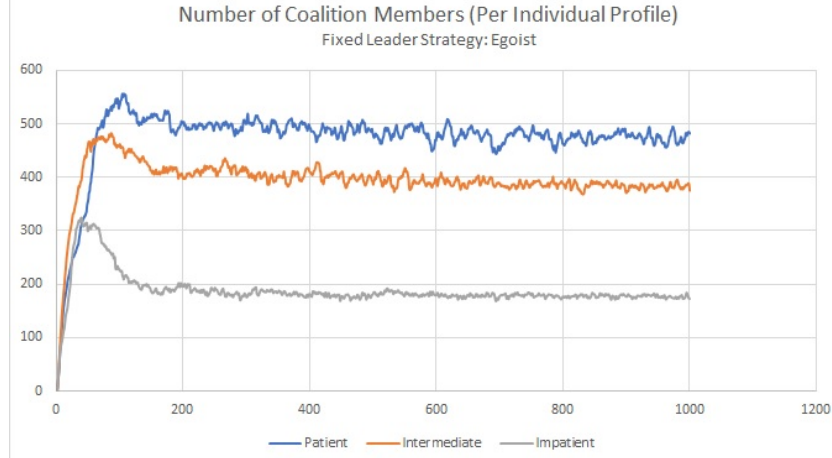

Figure 4. Number of Coalition Members Per Individual Profile (settings \#9, \#10 and \#11)

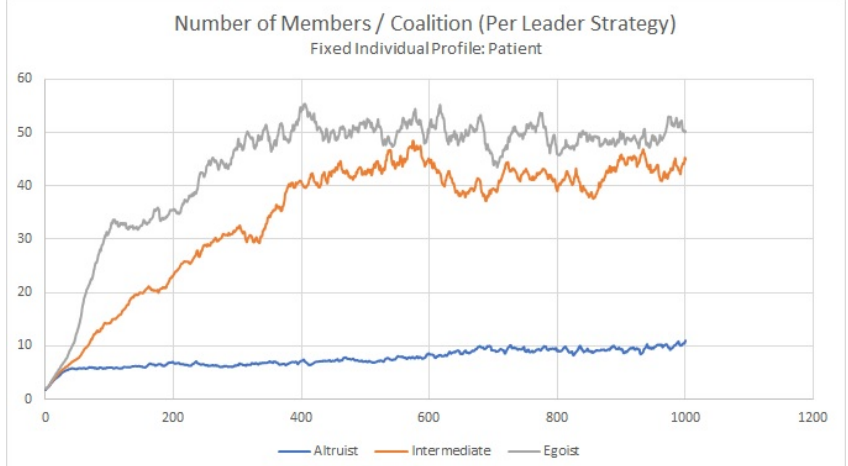

Figure 5. Number of Members / Coalition Per Leader Strategy (settings \#1, \#5 and \#9)

over the simulation rounds, as show in Figure 7 (blue line), which explains the higher standard deviations. In contrast, if the members of egoistic leaders' coalitions continue to increase their investments over many rounds, there will not be enough reward to compensate such investments, and hence the 'saturation point' is reached faster.

Moreover, it is interesting to notice that in scenarios with impatient individuals, in which both the numbers of coalitions and coalition members are lower, the amount of investments in coalitions is curiously high, as also illustrated in Figure 8. This occurs because an impatient individual gets satisfied only with a very high reward, which means that the individual's capital will grow faster, thus increasing his investment capacity. This becomes even more clear when we divide the total amount of investments by the number of coalition members, which is shown in Table 7 and Figures 9 and 10. The amount of investments per coalition member is much higher in the case of impatient individuals and it is very low in a scenario with altruistic leaders and patient individuals. The latter indicates that individuals do not stay too long in coalitions, since a coalition member only stays if he is receiving good rewards and, in this case, he would tend to increase his investment. Finally, in scenarios with mixed individual profiles, the results seem to be similar to those with intermediate individuals. However, scenarios with mixed leader strategies seem to be slightly more influenced by the presence of egoistic leaders, 


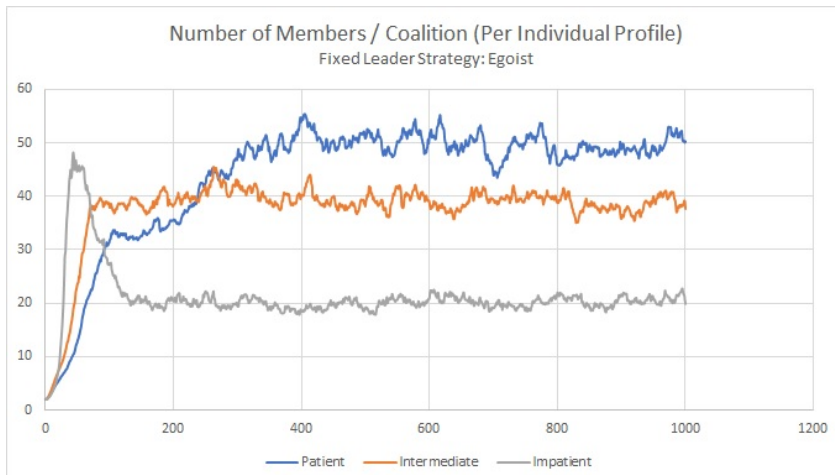

Figure 6. Number of Members / Coalition Per Individual Profile (settings \#9, \#10 and \#11)

so that the results are in-between the cases with exclusively intermediate and egoistic leaders.

Table 6. Total Investments in All Coalitions

\begin{tabular}{|c|c|c|c|c|}
\hline \multirow{2}{*}{$\begin{array}{c}\text { Individual } \\
\text { Profile }\end{array}$} & \multicolumn{4}{|c|}{ Leader Strategy } \\
\cline { 2 - 5 } Patient & Altruist & Intermed. & Egoist & Mixed \\
& 93 & 647 & 579 & 631 \\
& \pm 213 & \pm 226 & \pm 202 & \pm 194 \\
\hline Intermed. & 197 & 587 & 599 & 567 \\
& \pm 280 & \pm 196 & \pm 180 & \pm 165 \\
\hline Impatient & 351 & 566 & 528 & 510 \\
& \pm 262 & \pm 147 & \pm 170 & \pm 170 \\
\hline Mixed & 163 & 668 & 678 & 672 \\
& \pm 282 & \pm 149 & \pm 129 & \pm 132 \\
\hline
\end{tabular}

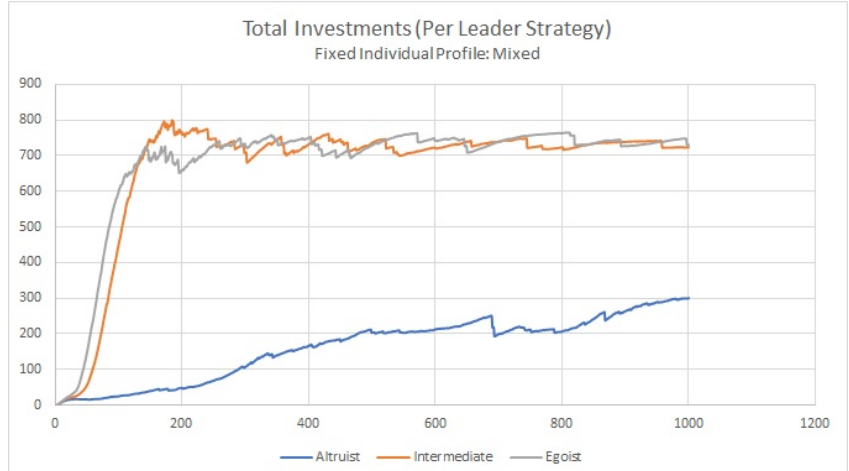

Figure 7. Total Investments Per Leader Strategy (settings \#4, \#8 and \#12)

Table 8 shows the average reward distributed per round. Since each of the 1000 individuals pay 1 of tax each round, the value that exceeds 1000 corresponds to the increase promoted by the leader through his gain factor. As different leaders have different gain factors, we can observe some oscillation in the total reward, but there is no discernible correlation between this value, the leaders' strategies and the individuals' profiles.

Finally, Table 9 presents the average capital that each individual holds, which is also illustrated in Figures 11 and 12. At first glance, we can notice that only in the case with altruistic

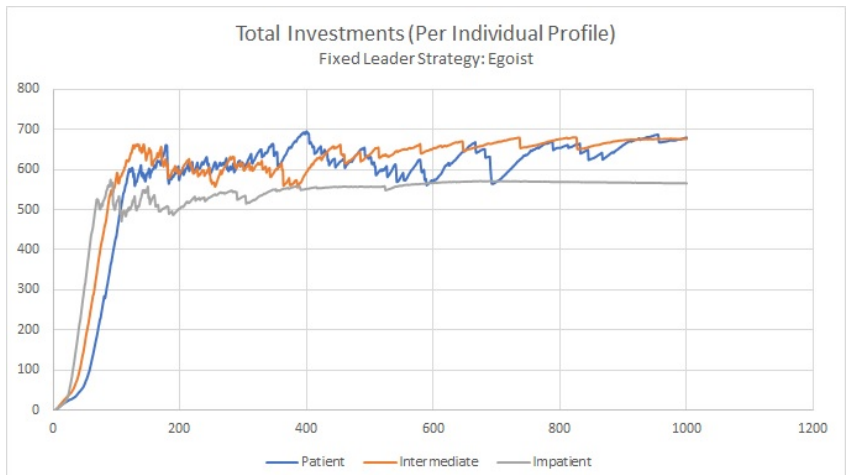

Figure 8. Total Investments Per Individual Profile (settings \#9, \#10 and \#11)

Table 7. Investment Per Coalition Member

\begin{tabular}{|c|c|c|c|c|}
\hline Individual & \multicolumn{4}{|c|}{ Leader Strategy } \\
\cline { 2 - 5 } Profile & Altruist & Intermed. & Egoist & Mixed \\
\hline Patient & 0.46 & 1.45 & 1.22 & 1.36 \\
\hline Intermed. & 0.82 & 1.56 & 1.51 & 1.48 \\
\hline Impatient & 2.29 & 3 & 2.79 & 2.77 \\
\hline Mixed & 0.84 & 1.94 & 1.9 & 1.93 \\
\hline
\end{tabular}

leaders the average capital is greater than the initial capital: as mentioned in Table 2, each individual receives a capital of 1000 at the beginning of the simulation. This occurs because once an individual invests in a coalition, the amount invested is spent on the 'campaign' of the leader and, since in scenarios with altruistic leaders individuals are not encouraged to invest in coalitions, less of the capital is spent on it. We can also observe that the available capital is lower with egoistic leaders, because they encourage more investments in coalitions. It is also lower with impatient individuals, because they invest larger amounts in coalitions, as previously identified.

\subsection{Distribution Analysis}

Table 10 presents how the capital, on average, is distributed among individuals at the end of a simulation (after 1000 rounds). Its values are different from Table 9, which shows the average capital available, per individual, throughout a simulation. As identified previously, the average capital available per individual is higher in a scenario with altruistic leaders

Table 8. Total Reward Distributed

\begin{tabular}{|c|c|c|c|c|}
\hline Individual & \multicolumn{4}{|c|}{ Leader Strategy } \\
\cline { 2 - 5 } Profile & Altruist & Intermed. & Egoist & Mixed \\
\hline Patient & 1267 & 1319 & 1243 & 1247 \\
& \pm 123 & \pm 103 & \pm 98 & \pm 86 \\
\hline Intermed. & 1299 & 1291 & 1250 & 1266 \\
& \pm 132 & \pm 76 & \pm 78 & \pm 91 \\
\hline Impatient & 1350 & 1263 & 1205 & 1218 \\
& \pm 131 & \pm 80 & \pm 109 & \pm 88 \\
\hline Mixed & 1285 & 1292 & 1255 & 1248 \\
& \pm 137 & \pm 71 & \pm 92 & \pm 82 \\
\hline
\end{tabular}




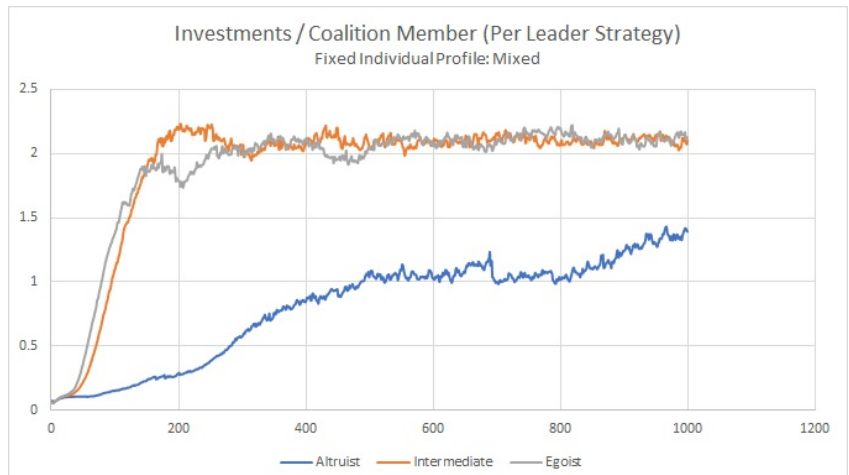

Figure 9. Investments / Coalition Member Per Leader Strategy (settings \#4, \#8 and \#12)

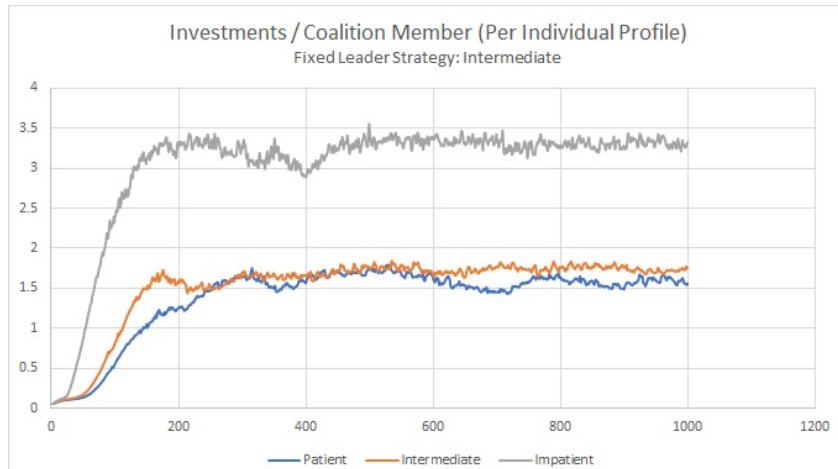

Figure 10. Investments / Coalition Member Per Individual Profile (settings \#5, \#6 and \#7)

and patient individuals. However, in the case of the analysis of distribution, the focus is on the standard deviation. Firstly, we can see that altruistic leaders promote a more egalitarian distribution, since the respective standard deviations are much lower. This occurs because they do not prioritize too much their coalitions, sharing benefits more equally, as well as inducing individuals to be less interested in joining coalitions. Another effect we can observe is that in the case of mixed leader strategies: such scenario seems to be even more unequal, possibly because those led by egoistic leaders benefit even more compared to others led by altruistic leaders. In Figure 13, we can observe that with altruistic leaders (orange

Table 9. Capital Available Per Individual

\begin{tabular}{|c|c|c|c|c|}
\hline \multirow{2}{*}{$\begin{array}{c}\text { Individual } \\
\text { Profile }\end{array}$} & \multicolumn{4}{|c|}{ Leader Strategy } \\
\cline { 2 - 5 } Patient & Altruist & Intermed. & Egoist & Mixed \\
& 1097 & 874 & 862 & 846 \\
& \pm 46 & \pm 56 & \pm 44 & \pm 49 \\
\hline Intermed. & 1074 & 881 & 852 & 870 \\
& \pm 60 & \pm 63 & \pm 55 & \pm 59 \\
\hline Impatient & 1040 & 865 & 853 & 866 \\
& \pm 57 & \pm 53 & \pm 65 & \pm 69 \\
\hline Mixed & 1077 & 841 & 812 & 816 \\
& \pm 67 & \pm 36 & \pm 37 & \pm 36 \\
\hline
\end{tabular}

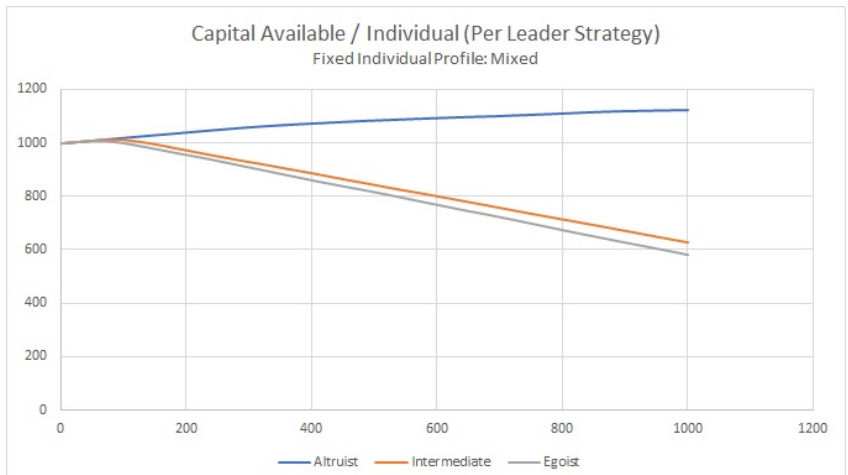

Figure 11. Capital Available / Individual Per Leader Strategy (settings \#4, \#8 and \#12)

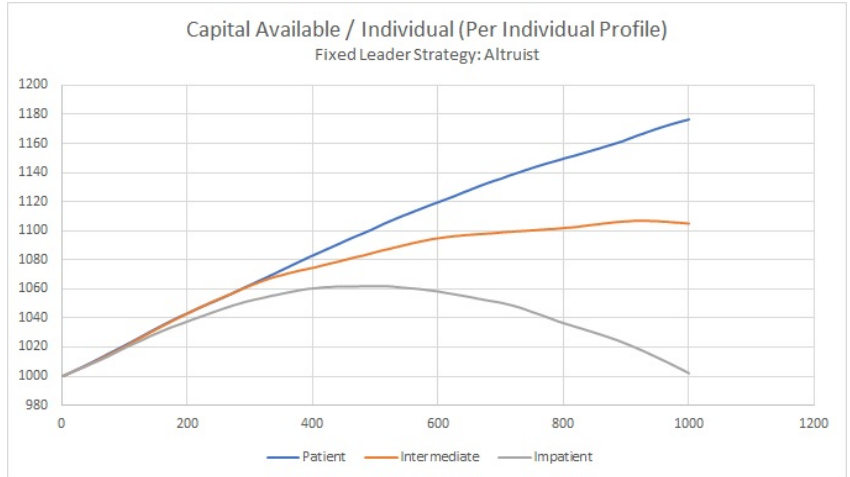

Figure 12. Capital Available / Individual Per Individual Profile (settings \#1, \#2 and \#3)

line), most individuals hold large amounts of capital, while in the case with mixed leaders (yellow line), many individuals hold small amounts of capital. Lastly, we can notice that the presence of the impatient profile implies more inequality. This is due to the fact that impatient individuals promote a tougher competition once they seek better rewards and the few of them who get satisfactorily large benefits end up concentrating the capital, as also illustrated in Figure 14.

Table 10. Distribution of Capital

\begin{tabular}{|c|c|c|c|c|}
\hline Individual & \multicolumn{4}{|c|}{ Leader Strategy } \\
\cline { 2 - 5 } Profile & Altruist & Intermed. & Egoist & Mixed \\
\hline Patient & 1177 & 675 & 667 & 619 \\
& \pm 149 & \pm 1346 & \pm 1418 & \pm 1338 \\
\hline Intermed. & 1105 & 707 & 654 & 702 \\
& \pm 427 & \pm 1879 & \pm 1700 & \pm 2041 \\
\hline Impatient & 1002 & 699 & 680 & 710 \\
& \pm 1198 & \pm 2280 & \pm 2327 & \pm 2530 \\
\hline Mixed & 1124 & 627 & 579 & 578 \\
& \pm 316 & \pm 1486 & \pm 1403 & \pm 1428 \\
\hline
\end{tabular}

Finally, in Table 11 we can see the average distribution of members among coalitions at the end of a simulation (after 1000 rounds). As previously indicated, coalitions are smaller in scenarios with altruistic leaders and impatient individuals and larger in the presence of egoistic leaders and patient 


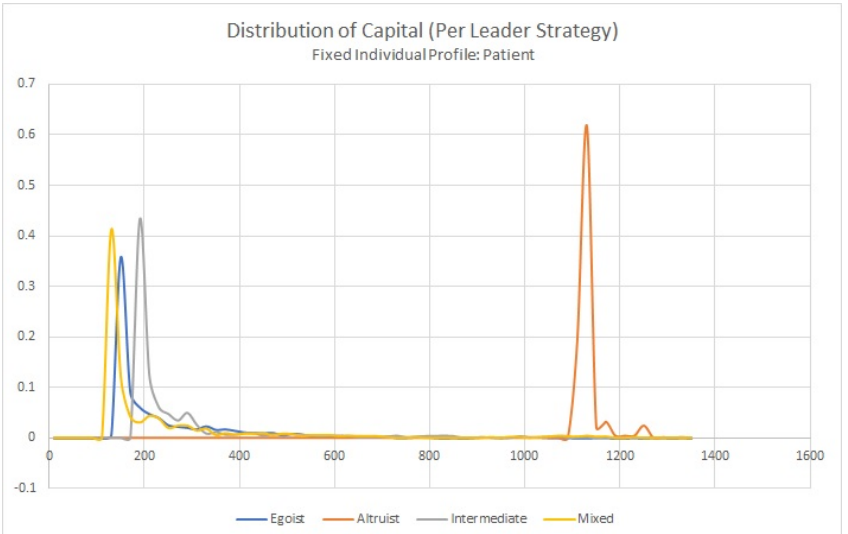

Figure 13. Distribution of Capital Per Leader Strategy (settings \#1, \#5, \#9 and \#13)

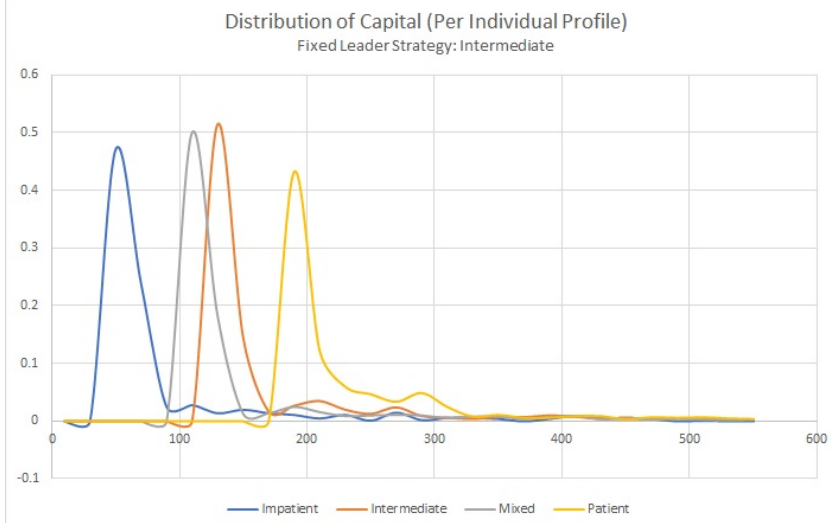

Figure 14. Distribution of Capital Per Individual Profile (settings \#5, \#6, \#7 and \#8)

individuals. However, we can observe in Table 11 that the standard deviations are higher with altruistic leaders and tend to be low in the case of impatient individuals. If one observes the graphics illustrated in Figures 15 and 16, it is easier to understand the shape of the distribution.

Even though there are many members in coalitions headed by egoistic leaders, as shown in Table 4, we can notice in Figure 15 that in this case (blue line) there are fewer small coalitions (with less than 20 members) compared to other leader strategies. On the other hand, we can also deduce that most of these coalition members are concentrated in large coalitions. For instance, if we consider the results from Tables 3 and 4, the average number of coalitions and coalition members for the setting depicted in Figure 15 (egoistic leaders and patient individuals) is respectively 12 and 474. Hence, we can derive from this Figure that we have approximately one single ${ }^{2}$ coalition with 170 members and another one with 100 members: this indicates that more than $50 \%$ of the 474 coalition members belong to large coalitions. This fact is in accordance with the previous analysis, since the large coalitions led by egoistic leaders end up centralizing the power and

\footnotetext{
${ }^{2}$ This corresponds roughly to $8 \%$ of the total of 12 coalitions.
}

therefore controlling the benefits.

Lastly, Figure 16 indicates that in the case of impatient individuals with intermediate leaders (blue line) the vast majority of coalitions are small (less than 40 members). This fact makes sense, since in this setting there are few coalitions (10) and also few coalition members (189), as shown in Tables 3 and 4. On the other hand, in scenarios with patient individuals (yellow line), small and large coalitions seem to co-exist, which follows from the fact that in this case there are more coalitions (15) and coalition members (447), as presented in Tables 3 and 4.

Thus, our results apparently indicate that the individual profile affects the number of coalitions and the number of coalition members, as previously observed; however, it apparently does not affect how those members are distributed among small and large coalitions.

Table 11. Distribution of Members Per Coalition

\begin{tabular}{|c|c|c|c|c|}
\hline Individual & \multicolumn{4}{|c|}{ Leader Strategy } \\
\cline { 2 - 5 } Profile & Altruist & Intermed. & Egoist & Mixed \\
\hline Patient & $9 \pm 13$ & $30 \pm 45$ & $37 \pm 51$ & $33 \pm 49$ \\
\hline Intermed. & $12 \pm 19$ & $29 \pm 32$ & $31 \pm 36$ & $32 \pm 35$ \\
\hline Impatient & $13 \pm 22$ & $18 \pm 20$ & $17 \pm 20$ & $17 \pm 19$ \\
\hline Mixed & $9 \pm 14$ & $24 \pm 28$ & $26 \pm 29$ & $26 \pm 29$ \\
\hline
\end{tabular}

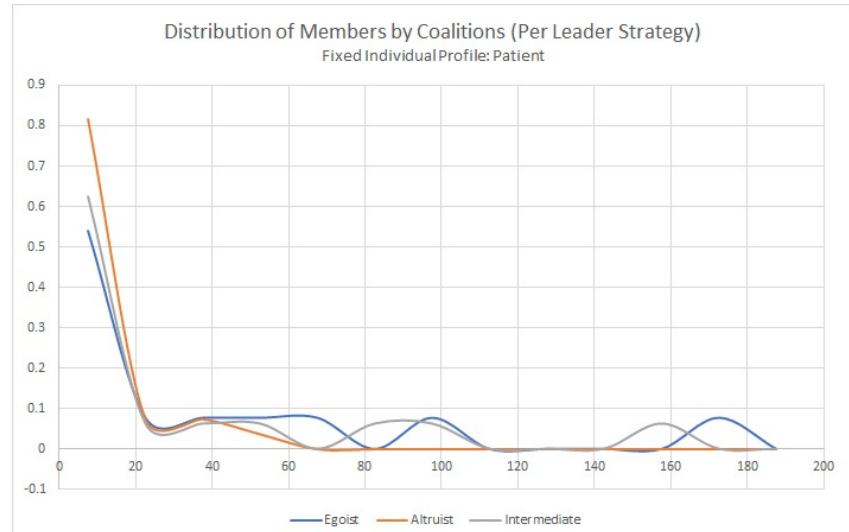

Figure 15. Distribution of Members by Coalitions Per Leader Strategy (settings \#1, \#5 and \#9)

\section{Conclusions}

This work presents a simplified model of a conventional political scenario in which representatives can decide how to distribute rewards among the population and can emerge from coalitions that support them financially. The results that we presented indicate that, in such context, certain leaders may cause more imbalances by distributing benefits more unequally. This intensifies the competition for rewards and consequently stimulates more individuals to participate in coalitions. Therefore, it would be necessary to create regulations in order to minimize such imbalances. However, fairer leaders could avoid further regulations because they make 


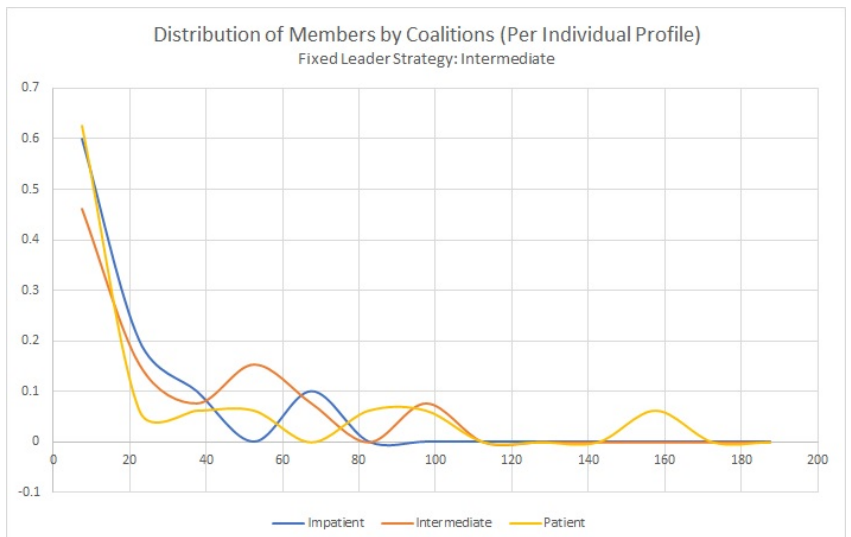

Figure 16. Distribution of Members by Coalitions Per Individual Profile (settings \#5, \#6 and \#7)

disputes for coalitions less attractive to individuals. Moreover, impatient individuals may also promote additional imbalances. Since they hardly get satisfied, this increases the competition and leads to a situation in which only a few receive great rewards and can invest ever larger amounts of capital. Their presence along with other profiles may cause even more inequality, leading to a higher concentration of capital.

In the next stages of this work, we are considering further enhancements to the model, possibly including some kind of voting system. In this way, investments in coalitions will no longer directly represent the likelihood of a leader's victory, but instead will influence the decisions of individuals over their votes. This would allow, for example, comparing the performance of different voting systems. Additionally, we could include in the model the possibility of having more than one representative per round, forming some kind of commission of representatives or even separating the population into districts. In this case, leaders could follow more complex strategies involving negotiation and it would be possible to observe what kind of strategies or groups would prevail.

\section{Acknowledgment}

Luís G. Ludescher is supported by CNPq, grant \# 132317/2016-8.

\section{Author Contributions}

Luís Gustavo Ludescher contributed with the research, model design and simulation, experiments, paper writing. Jaime Simão Sichman (advisor) contributed with guidance for research, development and experimentation, paper review and improvement.

\section{References}

[1] FISCHBACHER, U.; GÄCHTER, S.; FEHR, E. Are people conditionally cooperative? Evidence from a public goods experiment. Economics Letters, 2001.

[2] BURGER, N. E.; KOLSTAD, C. D. Voluntary public goods provision, coalition formation, and uncertainty. National Bureau of Economic Research Working Paper Series, 2009.
[3] HAMMAN, J. R.; WEBER, R. A.; WOON, J. An Experimental Investigation of Electoral Delegation and the Provision of Public Goods. American Journal of Political Science, 2011.

[4] GILENS, M.; PAGE, B. I. Testing theories of American politics: Elites, interest groups, and average citizens. Perspectives on Politics, 2014.

[5] SHEHORY, O.; KRAUS, S. Coalition formation among autonomous agents: Strategies and complexity (preliminary report). In: . [S.1.: s.n.], 2005.

[6] IEONG, S.; SHOHAM, Y. Marginal contribution nets: A compact representation scheme for coalitional games. In: Proceedings of the ACM conference on Electronic Commerce. [S.1.: s.n.], 2005.

[7] NARDIN, L. G.; ROSSET, L. M.; SICHMAN, J. S. Scale and Topology Effects on Agent-Based Simulation. In: . [S.1.: s.n.], 2014. [8] MUIS, J. Simulating political stability and change in the Netherlands (1998-2002): An agent-based model of party competition with media effects empirically tested. JASSS, 2010.

[9] VALKERING, P. et al. Modelling cultural and behavioural change in water management: an integrated, agent based, gaming approach. The Integrated Assessment Journal: Bridging Sciences \& Policy, 2009.

[10] SCHREIBER, D. The Emergence of Parties: An Agent-Based Simulation. Political Research Quarterly, 2014.

[11] LUDESCHER, L. G.; SICHMAN, J. S. Efeitos de estratégias de distribuição de recompensas em coalizões baseadas em agentes: resultados preliminares. In: . [S.1.: s.n.], 2019.

[12] SICHMAN, J. S. Operationalizing complex systems. In: Modeling complex systems for public policies. [S.1.: s.n.], 2015. cap. 5, p. 85-123.

[13] BARABÁSI, A.-1.; BONABEAU, E. Scale-free networks. Scientific American, v. 3, n. 1, p. 50-59, 2003.

[14] ALBERT, R.; BARABÁSI, A.-L. Statistical mechanics of complex networks. Reviews of Modern Physics, v. 74, n. 1, p. 47-97, 2002.

[15] NORTH, M. J. et al. Complex adaptive systems modeling with Repast Simphony. Complex Adaptive Systems Modeling, 2013.

[16] OZIK, J. et al. The ReLogo agent-based modeling language. In: 2013 Winter Simulations Conference (WSC). [S.1.: s.n.], 2013. p. 1560-1568. 